University of Wollongong

Research Online

Faculty of Commerce - Papers (Archive)

Faculty of Business and Law

Fall 5-2008

\title{
Mission or money? Competitive challenges facing public sector nonprofit organisations in an institutionalised environment.
}

Sara Dolnicar

University of Wollongong, s.dolnicar@uq.edu.au

H. J. Irvine

University of Wollongong, hirvine@uow.edu.au

K. Lazarevski

University of Wollongong, katiel@uow.edu.au

Follow this and additional works at: https://ro.uow.edu.au/commpapers

Part of the Finance and Financial Management Commons, Marketing Commons, and the Social and Behavioral Sciences Commons

\section{Recommended Citation}

Dolnicar, Sara; Irvine, H. J.; and Lazarevski, K.: Mission or money? Competitive challenges facing public sector nonprofit organisations in an institutionalised environment. 2008.

https://ro.uow.edu.au/commpapers/468

Research Online is the open access institutional repository for the University of Wollongong. For further information contact the UOW Library: research-pubs@uow.edu.au 


\title{
Mission or money? Competitive challenges facing public sector nonprofit organisations in an institutionalised environment.
}

\author{
Abstract \\ This paper exposes the impact of competitive grant funding on public sector nonprofit volunteer \\ organisations, using institutional theory to explain developments within this sector. A conceptual model is \\ developed from which five propositions are derived. Bushcare units, in experiencing institutional \\ pressures, respond in ways that affect their culture, structure and routines, resulting in the possibility that \\ their mission will be compromised. In the process of targeting competitive grants, preparing grant \\ applications, managing increased reporting requirements and recruiting volunteers, Bushcare units \\ should apply a mission "filter" to ensure their mission is not compromised in the pursuit of money. \\ Bushcare New South Wales (NSW), an Australian environmental organisation, provides an empirical \\ illustration of the proposed conceptual model.

\section{Keywords} \\ competitive grant funding, nonprofit volunteer organisations, institutional theory, environmental \\ organisations

\section{Disciplines} \\ Business | Finance and Financial Management | Marketing | Social and Behavioral Sciences

\section{Publication Details} \\ This article was originally published as Dolnicar, $\mathrm{S}$, Irvine, $\mathrm{H}$ and Lazarevski, $\mathrm{K}$, Mission or money? \\ Competitive challenges facing public sector nonprofit organisations in an institutionalised environment, \\ International Journal of Nonprofit and Voluntary Sector Marketing, 13, 2008, 107-117. Copyright John \\ Wiley 2008. Original journal available here
}




\title{
Mission or money? Competitive challenges facing public sector nonprofit organisations in an institutionalised environment.
}

Sara Dolnicar*a ${ }^{\mathrm{a}}$, Helen Irvine ${ }^{*^{\mathrm{b}}}$, Katie Lazarevski* ${ }^{\mathrm{a}}$

* Authors listed in alphabetical order.

${ }^{\mathrm{a}}$ School of Management \& Marketing, University of Wollongong; ${ }^{\mathrm{b}}$ School of Accounting and Finance, University of Wollongong.

\begin{abstract}
This paper exposes the impact of competitive grant funding on public sector nonprofit volunteer organisations, using institutional theory to explain developments within this sector. A conceptual model is developed from which five propositions are derived. Bushcare units, in experiencing institutional pressures, respond in ways that affect their culture, structure and routines, resulting in the possibility that their mission will be compromised. In the process of targeting competitive grants, preparing grant applications, managing increased reporting requirements and recruiting volunteers, Bushcare units should apply a mission "filter" to ensure their mission is not compromised in the pursuit of money. Bushcare New South Wales (NSW), an Australian environmental organisation, provides an empirical illustration of the proposed conceptual model.
\end{abstract}


[the public] want to believe that nonprofits do good works, are run by nice people in small homely organisations, where everybody calls each by their first names, the sun always shines and they do fantastic work all on a shoestring for little or no pay (Saxton, 2004, p. 189).

\section{INTRODUCTION}

This paper exposes the impact of competitive grant funding on a unique under-researched group of organisations: non-profits operating within the public sector. By operating across two sectors, public sector nonprofit organisations are subject to two sets of institutional influences. Changes in the public sector have resulted in a competitive, corporate approach (Funnell and Cooper, 1998), with implications for nonprofit organisations dependent on public sector funding. The dramatic increase in the number of nonprofit organisations over the last 20 years (Liao, et al., 2001) has led to a change in nonprofit culture from one of cooperation to one as "intensely competitive as commercial organisations" (Parker, 1998, p. 50). Furthermore, nonprofits have changed from "small" and "homely" to large and more sophisticated (Saxton, 2004, p. 189), adopting management and governance practices from the private sector (Alexander and Weiner, 1998, p. 223). This is due to changing patterns of government funding for nonprofit organisations which promote competition (Arnaboldi and Lapsley, 2004, Dart, 2004, Hall, 1990, Myers and Sacks, 2003).

A corporate model stresses "strategy development, risk taking, and competitive positioning" values, and has been identified as incompatible with the nonprofit model, which emphasises "community participation, due process, and stewardship" (Eikenberry and Kluver, 2004, p. 136). The challenge for nonprofits, especially those operating in the public sector, and relying heavily on government funding, is to manage competitive grant funding without sacrificing mission imperatives.

This challenge is illustrated by Bushcare New South Wales (NSW), an Australian environmental volunteering organisation dating from 1989 (Australian Association of Bush Regenerators, 2006), whose mission is to encourage and support community participation in conservation and restoration of local natural areas (Commonwealth of Australia, 2003). Increasingly, such organisations must demonstrate their fitness for funding by adopting societally legitimate behaviour. Paradoxically, this behaviour may compromise the mission they exist to serve. Bushcare, as a public sector nonprofit organisation, relies on council funding and competitive government grants, but possesses typical nonprofit features: it does not exist for profit, is mission-driven, and operates within the environmental volunteering field (Buchanan, et al., 2004, Gallagher and Weinberg, 1991), which is situated within the larger nonprofit sector (see Figure 1).

[Figure 1]

While large nonprofit organisations have been studied extensively (Irvine, 2000), public sector nonprofits have received little attention, a major research gap, since public sector nonprofits play a crucial role in implementing national priorities, such as the Australian government's environmental sustainability objectives. In 1997 the government 
committed \$1.25 billion over five years (Centre for International Economics, 1999) to work for the national interest to achieve conservation, sustainability and environmental repair through the Natural Heritage Trust (NHT). This catapulted small public sector nonprofits like Bushcare into a competitive grant funding environment, providing a unique illustration of the extent to which institutional pressures for corporate-style behaviour have permeated locally-based public sector nonprofits in competing for funding.

The first section of this paper presents an institutional framework, while the second provides an empirical illustration of this framework. Qualitative and quantitative data from Bushcare NSW illustrate evidence of competition, corporatisation and the potential jeopardisation of Bushcare's mission. Conclusions are drawn about the significance of this study, suggesting possibilities for future research.

\section{AN INSTITUTIONAL FRAMEWORK}

\section{Institutional theory}

Institutional theory acknowledges the importance of powerful societal rules, norms and expectations for organisational success (DiMaggio and Powell, 1983, Scott, 2001). Organisations within the same field (e.g. nonprofits) experience pressure to comply with coercive, normative and mimetic demands ${ }^{1}$ to adopt institutionally desirable practices. Facing similar issues and challenges, they become similar in their culture, structures and routines, in a process known as institutional isomorphism (Covaleski, et al., 1993, DiMaggio and Powell, 1983). Institutionalisation of corporate practices in recent years thus means that organisations across all sectors increasingly look the same.

\section{The institutionalised nonprofit environment}

Institutionalisation of competition and corporatisation in the public sector has led to a growing emphasis on corporate behaviour and outcomes in public sector management (Funnell and Cooper, 1998, Guthrie and English, 1997, Irvine, 2000, Josserand, et al., 2006). In the UK, for example, heightened competition and funding changes have seen public sector organisations exhibiting increased interest in marketing, recognising the need to develop "a more strategic, planning perspective" (Conway and Whitelock, 2004, p. 325). This change in focus, with the public sector adopting the "methods and values of the market to guide policy creation and management", has spilled over to the nonprofit sector, ushering in a new institutional environment for financially dependent nonprofit organisations (Hall-Taylor, 2001, Lyons, 1997).

The nonprofit sector worldwide is socially and economically significant, estimated in

\footnotetext{
${ }^{1}$ DiMaggio and Powell (1983) identified these three institutional "pillars": coercive (regulatory rules), normative (taken for granted societal norms including professionalisation) and mimetic (the copying of the behaviour of successful organisations).
} 
1995 to constitute a $\$ 1.1$ trillion industry (Salamon, et al., 1999) ${ }^{2}$. Nonprofit funding typically comes from a variety of sources, including fees, government grants, and philanthropy. These dependencies make them vulnerable to institutional pressures, as they are compelled to become "more market-like in their actions, structures, and philosophies" (Eikenberry and Kluver, 2004, p. 133), to act in a more entrepreneurial manner in order to attract resources for their cause (Mort, et al., 2003), and to adopt a more competitive and corporatised mode of operations (Covaleski and Dirsmith, 1988). This type of institutionally acceptable behaviour bestows legitimacy and proves organisations' fitness for funding (Ang and Cummings, 1997, Meyer and Rowan, 1977, Oliver, 1991).

This changing emphasis involves a strategic departure from traditional nonprofit culture, whose focus is on an altruistic, society-oriented and non-financial mission. However, evidence suggests adoption of corporate practices is not without problems for nonprofit organisations. In a study of sponsorship in nonprofits, the difficulty of making decisions that complied with both "normative frameworks and rules" and the demands of stakeholders (Daellenbach, et al., 2006, p. 81) was identified, raising the issue of the tension between the mission of nonprofits and the potential threat to that mission from institutional pressures.

\section{Institutionalised behaviour: a threat to mission?}

The adoption of the entrepreneurial practices of a competitive institutional environment can detract from the unique nature of nonprofits and threaten their mission (Schlesinger, et al., 2004). The contested concept of social entrepreneurship in nonprofits implies a corporate model with tolerance for risk, proactivity and innovation (Mort, et al., 2003), but can lead to problematic juxtaposition of risk-taking capitalistic behaviour with a mission of social concern. Replacing cooperation with competition (Eikenberry and Kluver, 2004), balancing "financial and operational objectives and organisational purpose" (Mort, et al., 2003, p. 80), and the need to infuse into nonprofit professionalisation "virtuous behaviour and judgement capacity" (Mort, et al., 2003, p. 81), all emphasise the need to balance mission and money.

Challenges to mission can arise with market orientation (Liao, et al., 2001), sponsorship acceptance (Daellenbach, et al., 2006), employment of professionals (Bennett and Savani, 2004), social entrepreneurship (Eikenberry and Kluver, 2004), or grant chasing, where "mission creep" sees organisations moving away from their original mission (Andreasen and Kotler, 2003, p. 353). Nonprofits may face an image crisis if they adopt corporate behaviour such as marketing (Saxton, 2004), so must be clear about their mission when adopting corporate behaviour (Rentschler and Potter, 1996, p. 105). Organisational culture (Demerath, 1998), internal organisational dynamics (Nelson, 1993), resource dependencies (Oliver, 1997), functional complexity, technical uncertainty

\footnotetext{
22 The size of the nonprofit sector can be compared to World GDP, which in 2000 was estimated by the World Bank at \$US31.8 trillion (World Development Indicators, 2006).
} 
and organisational size (Ang and Cummings, 1997) are some factors determining organisational response to institutional pressures, alongside clarity of and commitment to organisational mission.

Figure 2 encapsulates this discussion on the competitive funding environment, and presents a conceptual model of the behaviour of public sector nonprofit organisations operating in an institutional environment. Organisations can respond to coercive, normative and mimetic pressures in a variety of ways. Mission-astute organisations will "filter" those pressures to avoid compromising the mission (see left diagram in Figure 2). If no mission "filter" is applied, institutional pressures will be embedded in organisational culture, structures and routines and may lead to "mission creep" (Andreasen and Kotler, 2003, p. 67), (outlined above and on right in Figure 2).

[Figure 2]

Based on this institutionally grounded conceptual model, we propose that

- Bushcare units experience coercive, normative and mimetic institutional pressures (Proposition \#1);

- Bushcare units are experiencing changes in their culture (Proposition \#2);

- Bushcare units are experiencing changes in their structure (Proposition \#3);

- Bushcare units are experiencing changes in their routines (Proposition \#4);

- $\quad$ some Bushcare staff believe they are compromising the mission due to institutional pressures (Proposition \#5).

These propositions, investigated empirically for Bushcare NSW, illustrate the impact of competitive grant funding on an Australian nonprofit organisation operating within the public sector.

\section{AN EMPIRICAL ILLUSTRATION: BUSHCARE NSW}

Bushcare NSW was studied in a qualitative exploratory stage and a quantitative survey stage. In the qualitative phase, five in-depth interviews and two focus groups were conducted, based on a protocol developed from the seminal work of Meyer and Rowan (1977), DiMaggio and Powell (1983), and Scott (1995). The conceptual base of DiMaggio and Powell's (1983) coercive, normative and mimetic influences enabled description and analysis of organisational behaviour in a competitive bidding environment. An institutional theory researcher advised on this process, and all semistructured interviews and focus groups were based on these parameters. Questions were open-ended to explore the widest range of responses.

Given the dearth of institutionally-informed empirical work on nonprofit organisations operating in the public sector, all categories and questions used in the questionnaire were developed by the authors based on findings from the qualitative phase and following the 
parameters of institutional theory. The questionnaire was pilot tested with two industry experts, Bushcare coordinators, and nine adult respondents.

To increase the response rate, all fifty-four NSW Bushcare units were contacted first by telephone and asked about their willingness to participate in the survey. Questionnaires were mailed out in April 2005, with anonymity of respondents optional. Follow-up telephone calls were undertaken with Bushcare units that did not request anonymity and had not returned their questionnaire within three weeks. Forty-three questionnaires were completed and returned, a response rate of $80 \%$.

\section{Bushcare units experience coercive, normative and mimetic institutional pressures (Proposition \#1)}

Community Bushcare NSW programs are typically staffed by a skeleton staff paid by local councils, and rely on volunteers to achieve local environmental objectives. The impact of the NHT on community Bushcare has been huge, emphasising competition and professionalisation through competitive grants. The emphasis is now on strategic regional planning, a business-oriented approach, and effective monitoring of outputs and outcomes. Bushcare volunteer groups are encouraged to design, manage and evaluate their projects with progress reports. The Volunteer Coordinators Network (VCN), open to professional coordinators or facilitators of all community environmental programs, has assisted in this process.

NHT Envirofund distributed over $\$ 110$ million in competitive grants in the last four years (Australian Government: Department of the Environment and Heritage, 2004). This study's results indicated $91 \%$ of Bushcare NSW groups' grant applications under this scheme were successful. Additionally, the Australian government has urged nonprofits to exercise competitive entrepreneurship by making funding partnerships with business (Industry Commission, 1995). Since the focus of community Bushcare organisations is not on competitive corporate-style enterprise, most have had little preparation for such activities, except where local councils provide professional paid staff. Increasingly, professional staff manage local Bushcare units.

Coercive (funding rules and accountability guidelines), normative (the use of professional environmentalists to target, prepare and manage grants) and mimetic (the copying of Bushcare groups that have experienced grant success through publication of successful grant applications and VCN support) institutional pressures can thus be discerned in Bushcare's competitive funding environment. To the extent that Bushcare groups absorb these institutional pressures, they will experience changes in their organisational culture, structure and routines. 


\section{Bushcare units are experiencing changes in their culture (Proposition}

\#2)

Pressures for change, emanating from increasing emphasis on businesslike behaviour, were visible in the level of competition experienced by respondents and their awareness of funding competition. Tension was expressed between environmental aims and corporate operations, with some respondents passionate in their disapproval of the new centralised grant funding system that emphasised regional rather than local objectives. Respondents recognised marketing's value in raising community awareness of Bushcare's work, in particular to recruit volunteers. Marketing activities were undertaken by $62 \%$. The most effective recruitment methods identified were word of mouth, direct mail-outs and site signage. Half the Bushcare units stated that they budgeted an average of $9 \%$ of their total budget on recruitment, while $64 \%$ had "adopted or copied any recruitment activities that have been successful for other groups".

A strong sense of mission co-operation with other Bushcare groups was expressed by interviewees, and demonstrated by sharing strategies through the VCN. Although $10 \%$ of respondents perceived competition, the relationship between Bushcare coordinators was highly collegial and cooperative (Table 1).

[Table 1]

The VCN played an important role in sharing information and support regarding grant applications, with $58 \%$ of respondents regularly attending meetings. Of these, $96 \%$ were informed about grants at meetings, and $73 \%$ identified the VCN as a forum for learning how to prepare successful applications. Over half had copied the practices of successful groups. In spite of increasing competition, a strong cooperative culture exists, due to financial support from local councils, the availability of generous grant funding, and the nature of environmental volunteering and working for the common good.

Awareness of funding opportunities was high, with 98\% of respondents aware of NHT's Envirofund. Awareness was lower for corporate sponsorship or philanthropy funding. The belief that "it is easy for your organisation to gain grant funding" was verified by grant success rates ranging from $80 \%$ to $100 \%$. Although $50 \%$ believed gaining grant funding was easier five years ago, the vast majority (93\%) intended to apply in future, in response to pressure from colleagues, the professional environment and volunteers. While a strong sense of cooperation existed, there was also an expectation that greater entrepreneurship would assist in obtaining competitive grant funding. This transition in the relationship between these organisations could threaten the existing cooperative culture, and warrants further study. 


\section{Bushcare units are experiencing changes in their structure (Proposition \#3)}

Bushcare's affiliation with local councils makes it unique. The survey indicated $93 \%$ of groups had local government affiliation, with $95 \%$ of these in receipt of resources, and $80 \%$ receiving council supervision, training and/or staff salaries. Professional Bushcare environmental workers represented an additional organisational layer between councils and volunteers. VCN meetings strengthen these networks. Due to changes in grant schemes, paid professionals mediate council and grant funding body expectations to community volunteers, shielding them from administrative burdens. One respondent stated that he felt a lot of disincentive from volunteer members to participate in funding applications, while volunteers felt it was too difficult to help their Bushcare coordinator apply for funding due to increased competition.

Responsibility for grant applications therefore increasingly falls on professionals. Respondents stated that this task takes many days, requires considerable expertise and is very complicated. The survey revealed that almost $50 \%$ of applications were drafted by a professional worker, in most instances, by a full-time (83\%) or part-time (7\%) paid employee (see Table 2).

[Table 2]

Once simply groups of volunteers, Bushcare organisations have increased in sophistication, now including an additional organisational layer of professionals employed by local councils. These professionals mediate between the regulatory and funding bodies, and the local volunteers.

\section{Bushcare units are experiencing changes in their routines (Proposition \#4)}

Respondents associated increased competition with increases in administrative duties. Both positive and negative changes in operations due to competitive funding were noticed by $75 \%$ of respondents. Negative impacts included increases in administration, paperwork, accountability and more complex accounting. Grant funding, however, provided more opportunities for environmental work (see Table 3).

\section{[Table 3]}

Grant application and management took an average of $11 \%$ of coordinators' working time, as did training courses. Other duties identified included writing contracts, marketing/communication, management of officers and public relations. More recently respondents have felt pressure to conform to the strict NHT funding rules which they believed resulted in changes of time and responsibility allocation. Consensus on this issue was high. Respondents observed that indoor administrative duties, rather than outdoor 
work, now took up most of their time. Greater reporting and accountability demands of grant management have led to new routines being embedded in organisational practice. The preparation of the application involves detailed data, and implementation of grants requires coordinators to collect evidence such as photographs, weed maps, and numbers of trees planted to track the progress of the grant.

Bushcare culture is still cooperative, but institutional pressures for corporate behaviour require greater competition. Complex grant processes have changed the dynamics of Bushcare, requiring more professionalised operations. Bushcare officers have a vital role in preparing and managing grant applications and in buffering volunteers from regulatory requirements. Increasing professionalisation, a normative pressure, can bring substantial benefits to Bushcare groups, but highlights possible "mission creep" (Andreasen and Kotler, 2003) as institutional isomorphism occurs.

\section{Some Bushcare staff believe they are compromising the mission due to institutional pressures (Proposition \#5)}

Respondents noted grant funding rules emphasised a business-like approach. Frequent reference was made to the objectives of the grant funding, and the regional focus required to win grants. One Bushcare Coordinator explained that "bitou bush is a weed of national significance, it gives [the project] status in terms of funding. We have a Bushcare group working on Bitou bush in the area, we can say what we are doing is of regional focus. If you don't have that, how can you say that you are just pulling out weeds and would like some money?"

When asked about changes due to increased grant funding, respondents noted that "projects must be aligned with the objectives of the funding provider" and that they had to "try to fit grant limitations into a bush regeneration program". Thus volunteering organisations increasingly face the trade-off between their mission of bush conservation and regeneration and grant money. One respondent observed that grant applications required Bushcare to "satisfy needs of [the] funding body rather than the environment". Another stated that Bushcare was "often compelled to apply for resources of secondary importance, such as plants" and that "grants set priorities [that] may not agree with site priorities", requiring an adjustment of Bushcare's mission.

Incompatibility of grant requirements with longer term environmental goals was observed: "grants are all about money, Bushcare is about long term goals. Slow work does not fit the quick grant mentality". Some coordinators alleged that funding allocations for the clearing of new land potentially compromised environmental regeneration, which required working from the best part of the bush to the worst, not vice-versa. One stated that "clearing new land is a waste and takes years to obtain a level of re-vegetation sufficient for regeneration". Opposition to this institutional force was evidenced by refusal to apply for funding to clear new land: "we try not to [apply for clearance grants] and generally only apply for projects that meet Council's values and mission and exist in a current management plan". 
The survey confirmed findings from the qualitative data on the potential compromise of Bushcare's mission by revealing that Bushcare organisations with paid staff were more susceptible to having their goals compromised ( $\mathrm{p}$-value $<0.03$, chi-squared value $=6.3$, d.f. $=1$ ). A small number of Coordinators $(8 \%)$ did not plan to apply for grant funding, as financial support was still received from council and because of the perceived tension between mission and money: "[the] focus [of grants] on plants not regeneration, onerous reporting, aims modified".

Finally, Bushcare respondents were also asked directly whether they experienced "difficulty balancing the grant management with the mission of Bushcare" and whether there was "potential for the Bushcare goals to be compromised because of compliance with grant funding requirements". Almost half (46\%) perceived difficulties in balancing grant management with mission, and $38 \%$ saw potential for mission to be compromised.

Responses clearly illustrated the mission/money tension that many nonprofits face. Do they resist grant money and maintain commitment to their environmental regeneration mission or do they surrender to institutional pressures and compromise their best-practice methods? These tensions are evident even in a cooperative environment where pressure to adopt corporate practices is buffered by the level of funding available. This indicates significant implications for Bushcare's ability to perform its core mission in the future. It also highlights the role of Bushcare professionals in proactively managing grants while liaising with council and community volunteers.

\section{CONCLUSIONS}

A conceptual model, based on institutional theory, proposed that public sector nonprofits face coercive, normative and mimetic pressures. It further proposed that these pressures lead to changes in organisational culture, structures and routines which can lead to a position where staff perceive that the mission is compromised. Qualitative and quantitative data from individual Bushcare units supports the main propositions of this model. Bushcare units undergo competition and corporatisation of operating practices, with serious tensions between organisational mission and the grant funding received to fund that mission.

Organisations can choose a variety of responses to institutional pressures, depending on their funding dependencies and mission imperatives. In deciding whether to pursue competitive grant funding, Bushcare and other nonprofits need to make a careful assessment of whether funding rules are mission-appropriate, by applying a mission "filter" to the institutional pressures they experience (see left diagram in Figure 2). Identifying organisational purpose is profoundly important, and Bushcare participants need to be clear about their mission to avoid "mission creep" (Andreasen and Kotler, 2003). Volunteers are usually mission-driven, but are rarely grant applicants. Professional Bushcare employees, who usually prepare applications, have to be able to assess the mission-compatibility of grant schemes. By having a volunteer centred mindset, and a mission that is feasible, motivating and distinctive (Andreasen and Kotler, 2003), they can achieve synchronisation between mission imperatives and grant funding. 
Our study is limited by its restriction to Bushcare NSW and the cross-sectional nature of the research design. Future work testing the model for all Bushcare units in Australia or other public sector non profit organisations would be very valuable. A longitudinal study would enable actual testing of the causal effect of the three pressures postulated by institutional theory to cause organisational changes. 


\section{REFERENCES}

Alexander JA, Weiner BJ. 1998. The Adoption of the Corporate Governance Model by Nonprofit Organizations. Nonprofit Management \& Leadership 8: 223-42.

Andreasen AR, Kotler P. 2003. Strategic Marketing for Nonprofit Organizations. 6th ed. Prentice Hall: Upper Saddle River, NJ.

Ang S, Cummings LL. 1997. Strategic Response to Institutional Influences on Information Systems Outsourcing. Organization Science 3: 235-56.

Arnaboldi M, Lapsley I. 2004. Modern Costing Innovations and Legitimation: A Health Care Study. Abacus 40: 1-20.

Australian Association of Bush Regenerators. 2006.

http://www.aabr.org.au/index.php?option=com_content\&task=view\&id=17\&Itemid=49 [7 September 2006].

Australian Government: Department of the Environment and Heritage. 2004. [15 March 2005]. 
Bennett R, Savani S. 2004. Managing Conflict between Marketing and Other Functions within Charitable Organizations. The Leadership and Organization Development Journal 25: $180-200$.

Buchanan J, Carter L, Ng S. 2004. Marketing and Ethics in Not for Profit Organisations: An Australian Study, The Australian and New Zealand Marketing Academy (ANZMAC) Conference 2004. New Zealand: The Australian and New Zealand Marketing Academy (ANZMAC).

Centre for International Economics. 1999.

http://www.nht.gov.au/review/mtrfinrpt/pubs/bushcare.pdf [March 2004].

Commonwealth of Australia. 2003. http://www.nht.gov.au [February 2004].

Conway T, Whitelock J. 2004. Can Relationship Marketing Enhance Strategic Thinking in the Public Sector? A Study of the Perceived Relationship between Subsidised Theatres and Their Government Funders/Regulators. International Journal of Nonprofit and Voluntary Sector Marketing 9: 320-34.

Covaleski MA, Dirsmith MW. 1988. An Institutional Perspective on the Rise, Social Transformation, and Fall of a University Budget Category. Administrative Science Quarterly 33: 562-87. 
Covaleski MA, Dirsmith MW, Michelman JE. 1993. An Institutional Theory Perspective on the Drg Framework Case-Mix Accounting Systems and Health-Care Organizations. Accounting, Organizations and Society 18: 65-80.

Daellenbach K, Davies J, Ashill NJ. 2006. Understanding Sponsorship and Sponsorship Relationships - Multiple Frames and Multiple Perspectives. International Journal of Nonprofit and Voluntary Sector Marketing 11: 73-87.

Dart R. 2004. Being 'Business-Like' in a Nonprofit Organization: A Grounded and Inductive Typology. Nonprofit and Voluntary Sector Quarterly 33: 290 - 310.

Demerath NJI. 1998. Snatching Defeat from Victory in the Decline of Liberal Protestantism. Culture Versus Structure in Institutional Analysis. Oxford University Press: New York.

DiMaggio P, Powell WW. 1983. The Iron Cage Revisited: Institutional Isomorphism and Collective Rationality in Organizational Fields. American Journal of Sociology 48: 14760.

Eikenberry AM, Kluver JD. 2004. The Marketization of the Nonprofit Sector: Civil Society at Risk? Public Administration Review 64: 132-40.

Funnell W, Cooper K. 1998. Public Sector Accounting and Accountability in Australia. University of New South Wales Press Ltd: Sydney, Australia. 
Gallagher K, Weinberg CB. 1991. Coping with Success: New Challenges for Nonprofit Marketing. Sloan Management Review 33: 27-42.

Guthrie J, English L. 1997. Performance Information and Programme Evaluation in the Australian Public Sector. International Journal of Public Sector Management 10: 154-64.

Hall-Taylor B. 2001. The Corporatization of the Australian University. On The Horizon 4: 5-7.

Hall PD. 1990. Conflicting Managerial Cultures in Nonprofit Organizations. Nonprofit Management and Leadership 1: 153-65.

Industry Commission. 1995. Charitable Organisations in Australia. Australian Government Publishing Service: Sydney, Australia.

Irvine H. 2000. Powerful Friends: The Institutionalisation of Corporate Accounting Practices in an Australian Religious / Charitable Organisation. Third Sector Review 6: 526.

Josserand E, Teo S, Clegg S. 2006. From Bureaucratic to Post-Bureaucratic: The Difficulties of Transition. Journal of Organizational Change Management 19: 54-64. 
Liao MN, Foreman S, Sargeant A. 2001. Market Versus Societal Orientation in the Nonprofit Context. International Journal of Nonprofit and Voluntary Sector Marketing 6: 254-68.

Lyons M. 1997. Contracting for Care: What Is It and What Is at Issue? Third Sector Review 3: 205-15.

Meyer JW, Rowan B. 1977. Institutionalized Organizations: Formal Structure as Myth and Ceremony. American Journal of Sociology 82: 340-63.

Mort GS, Weerawardena J, Carnegie K. 2003. Social Entrepreneurship: Towards Conceptualization. International Journal of Nonprofit and Voluntary Sector Marketing 8: 76-88.

Myers J, Sacks R. 2003. Tools, Techniques and Tightropes: The Art of Walking and Talking Private Sector Management in Non-Profit Organisations, Is It Just a Question of Balance? Financial Accountability \& Management 19: 287-305.

Nelson RE. 1993. Authority, Organization, and Societal Context in Multinational Churches. Administrative Science Quarterly 38: 653-82.

Oliver C. 1991. Strategic Responses to Institutional Processes. The Academy of Management Review 16: 145-79. 
Oliver C. 1997. Sustainable Competitive Advantage: Combining Institutional and Resource-Based Views. Strategic Management Journal 18: 697-713.

Parker L. 1998. Non-Profit Prophets: Strategy in Non-Commercial Organizations. Australian CPA 68: 50-52.

Rentschler R, Potter B. 1996. Accountability Versus Artistic Development. The Case for Non-Profit Museums and Performing Arts Organizations. Accounting, Auditing \& Accountability Journal 9: 100-13.

Salamon LM, Anheier HK, List R, Toepler S, Sokolowski SW. 1999. Global Civil Society. Dimensions of the Nonprofit Sector. The Johns Hopkins Center for Civil Society Studies: Baltimore.

Saxton J. 2004. Editorial: The Achilles' Heel of Modern Nonprofits Is Not Public ‘Trust and Confidence' but Public Understanding of 21st Century Charities. International Journal of Nonprofit and Voluntary Sector Marketing 9: 188-90.

Schlesinger M, Mitchell S, Gray BH. 2004. Restoring Public Legitimacy to the Nonprofit Sector: A Survey Experiment Using Descriptions of Nonprofit Ownership. Nonprofit and Voluntary Sector Quarterly 33: 673-710.

Scott WR. 2001. Institutions and Organizations. Second ed. Sage Publications: Thousand Oaks, USA. 
Scott WR. 1995. Institutions and Organizations. Sage Publications: Thousand Oaks, USA.

World Development Indicators. 2006.

http://web.worldbank.org/WBSITE/EXTERNAL/DATASTATISTICS/0,, contentMDK:2 0899413 pagePK:64133150 piPK:64133175 theSitePK:239419,00.html [December 2006]. 
FIGURES

Figure 1: Bushcare's unique location across public and nonprofit sectors

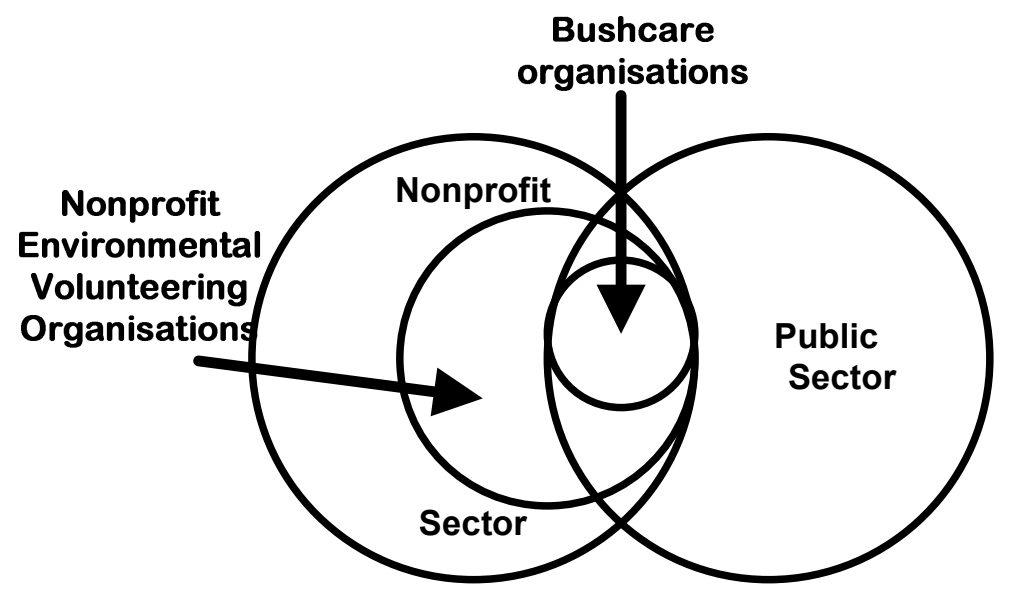


Figure 2: Organisational response to institutional pressures in a competitive environment

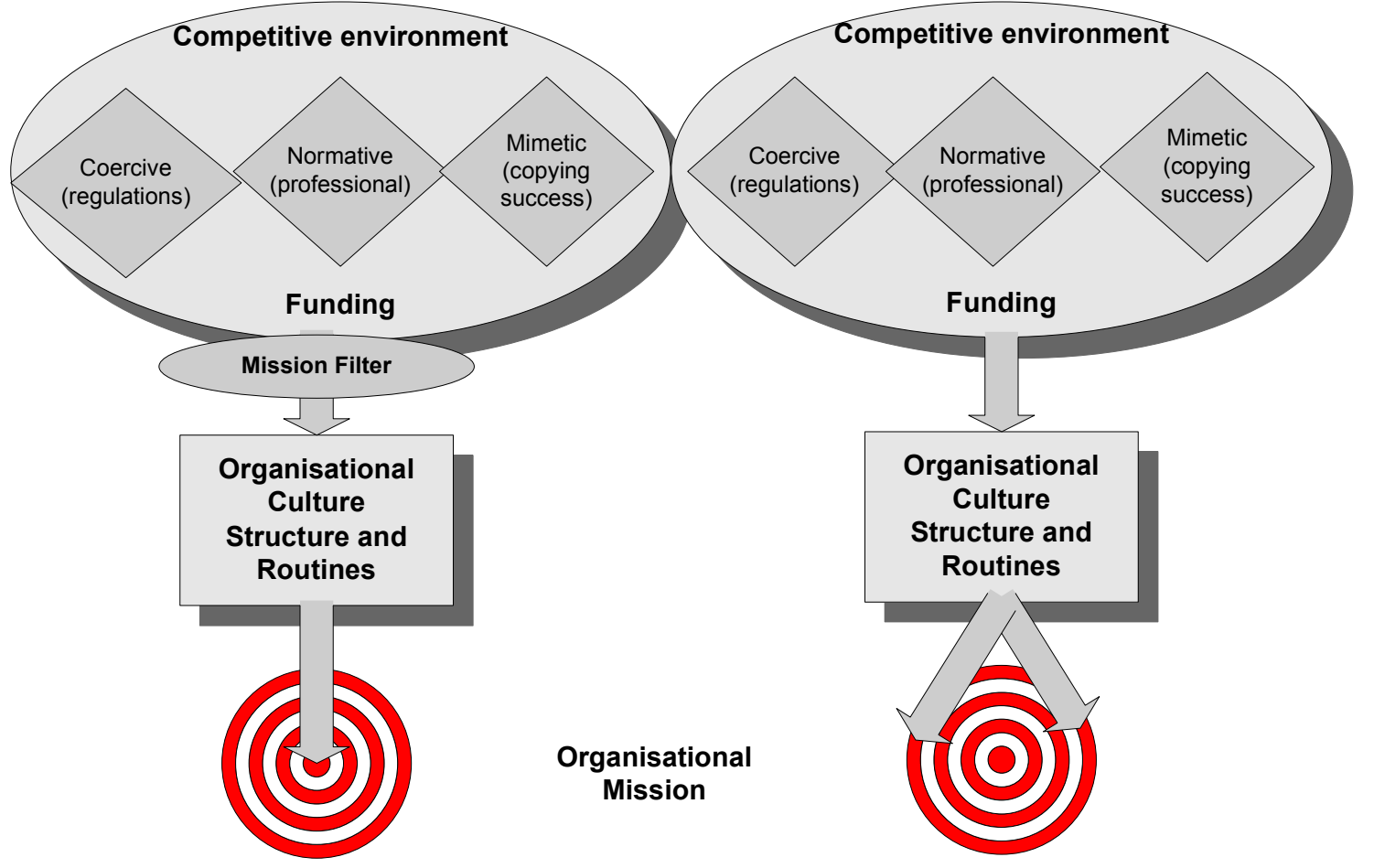

Applying the mission filter

Not applying the mission filter 


\section{TABLES}

Table 1: Relationships with other Bushcare units.

$\begin{array}{ll}\text { Description } & \text { \% of respondents } \\ \text { Helpful } & 95 \\ \text { Supportive } & 85 \\ \text { Friendly } & 80 \\ \text { Cooperative } & 79 \\ \text { Professional } & 73 \\ \text { Informative } & 71 \\ \text { Open } & 68 \\ \text { Competitive } & 13 \\ \text { Reserved } & 3 \\ \text { Distant } & 3\end{array}$


Table 2: Preparation of grant applications.

\section{Who prepares grant application \\ $\%$ of respondents}

A Bushcare Coordinator drafts a grant application $\quad 49 \%$

A Bushcare Officer drafts a grant application $\quad 44 \%$

Person to create draft is a full-time paid employee $\quad 83 \%$

Person to create draft is a part-time paid employee $\quad 7 \%$

Bushcare Coordinator creates final grant application $\quad 49 \%$

Bushcare Officer creates final grant application $\quad 37 \%$

Person to create final is a full-time paid employee $\quad 83 \%$

Person to create final is part-time paid employee $\quad 7 \%$ 
Table 3: Changes in Bushcare operations in consequence of grant funding. Changes in organisational routines $\%$ of respondents

More administration activities due to awarded funding $\quad 85$

More paperwork due to awarded funding $\quad 78$

More opportunities due to awarded funding $\quad 68$

More accountable due to awarded funding 65

More complex accounting due to change 65

More reporting due to awarded funding 63

More complex reporting due to change 63

More reporting to funding body due to change $\quad 60$

More time in office due to awarded funding 53

More resources due to awarded funding 38

More volunteers due to awarded funding $\quad 30$

More equipment due to awarded funding 26

None of the above changes due to awarded funding 3 